\title{
A SEROLOGICAL SURVEY OF HUMAN CORONAVIRUS IN PIGS OF THE TOHOKU DISTRICT OF JAPAN
}

\author{
N. Hirano and K. Ono \\ Department of Veterinary Microbiology \\ Iwate University \\ Morioka, Japan
}

\section{ABStraCT}

A total of 2496 swine sera from 60 farms in the Tohoku District of Japan was examined for hemagglutination inhibiting (HI) antibodies to human coronavirus (HCV), swine hemagglutinating encephalomyelitis virus (HEV) and bovine coronavirus (BCV). HI antibodies to HCV OC43 strain and HEV $67 \mathrm{~N}$ strain were highly prevalent with positivity rates of 91.4 and $82.1 \%$, respectively, while the BCV Kakegawa strain was $44.2 \%$ positive. Farm D in Miyagi Prefecture showed the highest antibody titers to HCV OC43 strain with geometric mean titers (GMT) of 1:200. These results suggest that pigs might be infected with $\mathrm{HCV}$ or an antigenetically related virus as well as HEV.

\section{INTRODUCTION}

Coronaviruses infect a wide variety of animal species, including avian and also human beings, and causes respiratory disease, enteritis, hepatitis or encephalitis. Among the swine coronaviruses, transmissible gastroenteritis virus, porcine epidemic diarrhea virus and HEV are well known. Notably, HEV infection in pigs has been reported as globally common by serological surveys. In Japan (Hirai et al., 1974) it was first reported that about $50 \%$ of the swine sera collected were positive for HI antibodies to HEV 67N strain. In 1987 in Japan $\mathrm{HEV}$ was first isolated from piglets in farms showing about $50 \%$ seropositivity to the virus (Hirahara., 1987). To see the prevalence of antibodies to HEV, we undertook serological surveys for HEV in 60 farms of the Tohoku District by $\mathrm{HI}$ tests. In addition to HEV, we also surveyed for $\mathrm{HCV}$ and $\mathrm{BCV}$ in swine sera. The results showed that $\mathrm{HI}$ antibodies to $\mathrm{HCV}$ was higher in seropositivities and titers than those of $\mathrm{HEV}$ or BCV. 


\section{MATERIALS AND METHODS}

\subsection{Serum Samples}

From 1985 to 1988, 2,469 sera were collected from pigs of 60 farms in Aomori, Iwate, Akita and Miyagi Prefectures. These sera were heated at $56^{\circ} \mathrm{C}$ for 30 minutes, and mixed with an equal volume of $25 \%$ kaolin solution in phosphate buffered saline (PBS, $\mathrm{pH}$ 7.2). After centrifugation, the supernatant was mixed with an equal volume of $25 \%$ chicken red blood cell (CRBC) suspension in PBS and incubated at $20^{\circ} \mathrm{C}$ for $30 \mathrm{~min}$. After centrifugation, the serum samples were used as a 1:4 dilution of the original.

\subsection{Virus}

The virus strains used in this study were HCV OC436(HCV-OC43), HEV 67N7(HEV-67N) and BCV Kakegawa (Hirano et al., 1985) (BCV-K) strains. As virus antigen, supernatant of infected mouse brain homogenates was used for HCV OC43, and infected culture fluid of SK-K for HEV 67N and of BEK-1 cells for BCV-K.

\subsection{HI Test}

The test was carried out in 96-well microplates using $0.5 \%$ CRBC in PBS. An HI titer of $1: 8$ or higher was recorded as positive.

\section{RESULTS}

\section{HI Antibodies in Swine Sera to HCV-OC43, HEV-67N, and BCV-K}

As shown in Table 1, 2,257 (91.4\%), 2,028 (82.1\%) and 1,092 out of 2,469 sera were positive for $\mathrm{HCV}-\mathrm{OC} 43, \mathrm{HEV}-67 \mathrm{~N}$ and $\mathrm{BCV}-\mathrm{K}$, respectively, in 4 Prefectures. The GMT for HCV-OC43, HEV-67N and BCV-K was 1:45, 1:43 and 1: 18. Among three viruses, HCV-OC43 showed the highest positive rate of $91.4 \%$ and a GMT of $1: 45$. The positive rates and the GMT for HCV-OC43 ranged from 86.2\% (425/493) in Aomori to 94\% (498/530) in Akita Prefecture, and from 1:37 in Akita to 1:59 in the Miyagi Prefecture, respectively.

Table 2 indicates swine farms showing the highest antibody titers for HCV-OC43 in each Prefecture. Farm A (Aomori), B (Iwate), C (Akita) and D (Miyagi Prefecture) had higher positive rates and antibody titers than those of HEV-67N or BCV-K. Farm D showed the highest GMT of 1:200 in 42 of 42 sera, whose antibody titers varied from 1:8 to $1: 1028$.

\section{DISCUSSION}

In 1974, Hirai et al conducted a serological survey on HEV infection in pigs in Japan, revealing that about $50 \%$ of all pigs in Japan and $27 \%$ those in the Tohoku District were positive for HEV-67N. In the present study, $82 \%$ of animals in the Toholu District were shown to be positive for HEV-67N. However, no clinical disease was observed in 
Table 1. HI antibodies in swine sera to HCV-OC43, HEV-67N, and $\mathrm{BCV}-\mathrm{K}$

\begin{tabular}{llccc}
\hline Virus & Prefecture & Positive/tested & $(\%)$ & GMT \\
\hline HCV-OC43 & Aomori & $425 / 493$ & $(86.2)$ & $52^{\mathrm{a}}$ \\
& Iwate & $681 / 738$ & $(92.3)$ & 38 \\
& Akita & $498 / 530$ & $(94.0)$ & 37 \\
& Miyagi & $653 / 708$ & $(92.2)$ & 59 \\
& Total & $2257 / 2469$ & $(91.4)$ & 45 \\
HEV-67N & Aomori & $424 / 493$ & $(86.0)$ & 74 \\
& Iwate & $640 / 738$ & $(86.2)$ & 26 \\
& Akita & $337 / 530$ & $(63.6)$ & 29 \\
& Miyagi & $627 / 708$ & $(82.1)$ & 43 \\
& Total & $2028 / 2469$ & $(82.1)$ & 43 \\
BCV-K & Aomori & $320 / 493$ & $(64.9)$ & 25 \\
& Iwate & $258 / 783$ & $(35.0)$ & 13 \\
& Akita & $102 / 530$ & $(19.2)$ & 15 \\
& Miyagi & $412 / 708$ & $(58.2)$ & 17 \\
& Total & $1092 / 2469$ & $(44.2)$ & 18 \\
\hline
\end{tabular}

${ }^{\mathrm{a}}$ Reciprocal titer

any of the 60 farms examined. These results indicate that HEV might cause as inapparent form of infection in pigs.

Interestingly, $\mathrm{HI}$ antibodies to $\mathrm{HCV}-\mathrm{OC} 43$ were detected in pigs at a higher incidence than antibodies to HEV-67N and BCV-K. Farm D in the Miyagi Prefecture showed the highest GMT of 1:200, suggesting that $\mathrm{HCV}$ or an antigenitically related virus might be responsible for $\mathrm{HI}$ antibodies to $\mathrm{HCV}-\mathrm{OC} 43$ in 42 pigs. Kaye et al reported antibody responses to HCV-OC43 and HEV-67N in human and animal sera, and demonstrated that sera from veterinary students and meat producers showed higher titers of $\mathrm{HI}$ antibodies to HEV-67N than those of college students, suggesting the possibility of HEV exposure in humans.

The present study demonstrated that swine sera showed high antibody titers and seropositiviticates for $\mathrm{HCV}-\mathrm{OC} 43$ as well as $\mathrm{HEV}-67 \mathrm{~N}$, suggesting the possibility that $\mathrm{HCV}$ or antigenitically related virus might infect pigs.

Table 2. Swine farms showing high antibody titers to HCV-OC43

\begin{tabular}{lllcr}
\hline Farm & (Prefecture) & \multicolumn{1}{c}{ Virus } & Positive/tested (\%) & GMT \\
\hline A & (Aomori) & HCV-OC43 & $30 / 30(100)$ & 75 \\
& & HEV-67N & $25 / 30(83.3)$ & 23 \\
& & BCV-K & $13 / 30(43.3)$ & 9 \\
B & (Iwate) & HCV-OC43 & $120 / 120(100)$ & 95 \\
& & HEV-67N & $95 / 120(79.2)$ & 20 \\
& & BCV-K & $39 / 120(32.5)$ & 10 \\
C & (Akita) & HCV-OC43 & $19 / 19(100)$ & 59 \\
& & HEV-67N & $15 / 19(78.9)$ & 22 \\
& & BCV-K & $0 / 19$ & \\
D & (Miyagi) & HCV-OC43 & $42 / 42(100)$ & 200 \\
& & HEV-67N & $42 / 42(100)$ & 36 \\
& & BCV-K & $42 / 42(100)$ & 19 \\
\hline
\end{tabular}

${ }^{\mathrm{a}}$ Reciprocal titers 


\section{REFERENCES}

Hirai, K., Chang, C. N. and Shimakura, S., 1974, A serological survey on hemagglutinating encephalomyelitis virus infection in pigs in Japan, Jpn. J. Vet. Sci. 36: 375-382.

Hirahara, T., Yasuhara, H., Kodama, K., Nakai, M. and Sasaki, N., 1987, Isolation of hemagglutinating encephalomyelitis virus from respiratory tract of pigs in Japan, Jpn. J. Vet. Sci. 49: 85-93.

Hirano, N., Ono, K., Takasawa, H., Murakami, T. and Haga, S. J., 1990, Replication and plaque formation of swine hemagglutinating encephalomyelitis virus $(67 \mathrm{~N})$ in swine cell line, SK-K culture, J. Virol. Meth. 27: 91-100.

Hirano, N., Sada, F., Tsuchiya, K., Ono, K. and Murakami, T., 1985, Plaque assay of bovine coronavirus in BEK-1 cells, Jpn. J. Vet. Sci. 47: 679-681.

Kaye, H. S., Yarbrough, W. R., Reed, C. J. and Harrison, A. K. J., 1977, Antigenic relationship between human coronavirus strain OC 43 and hemagglutinating encephalomyelitis virus strain $67 \mathrm{~N}$ of swine: antibody responses in human and animal sera, Inf. Dis. 135: 201-209.

McIntosh, K., Dees, J. H., Becker, W. B., Kapikian, A. Z. and Chanock, R. M., 1967, Recovery in tracheal organ cultures of novel viruses from patients with respiratory disease, Proc. Natl. Acad. Sci. USA 57: 933-940.

Mengeling, W. L., Boothe, A. D. and Richte, A. E., 1972, Characteristics of a coronavirus (Strain 67N) of pigs, Am. J. Vet. Res. 33: 297-308. 